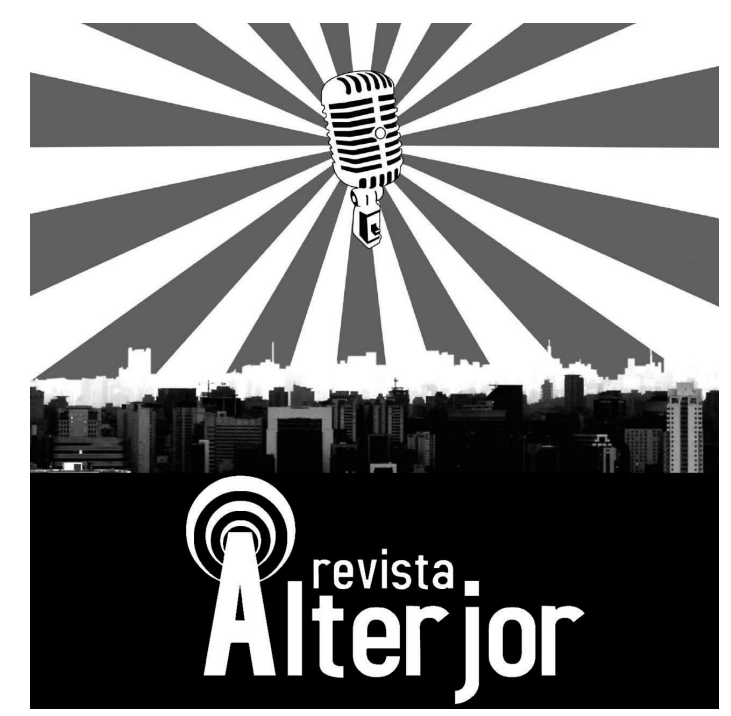

\title{
FLUXOS COMUNICACIONAIS ÀS AVESSAS: DO LOCAL PARA O NACIONAL E VICE-VERSA
}

\section{Gustavo Teixeira de Faria Pereira ${ }^{1}$ \\ Iluska Coutinho ${ }^{2}$}

\begin{abstract}
RESUMO: O objetivo do presente trabalho é analisar o Brasil em Rede, telejornal que se apresentava como sendo de âmbito local, ainda que fosse veiculado em uma emissora pública regional. O programa jornalístico foi veiculado entre dezembro de 2017 e janeiro de 2019 na Rede Minas, emissora regional de Minas Gerais, e contava com produções de emissoras parcerias de todo o Brasil para que o noticiário fosse diariamente ao ar. Como metodologia utilizamos a Análise da Materialidade Audiovisual (COUTINHO, 2016), que busca investigar o audiovisual como uma unidade e sem decomposição e como resultados preliminares temos a possibilidade de promoção de novos olhares e vozes no telejornalismo brasileiro em que a maior parte dos telejornais nacionais são produzidos a partir do eixo Rio de Janeiro-São Paulo-Brasília e o pioneirismo de um movimento às avessas de promoção de um telejornal nacional a partir de uma emissora regional.
\end{abstract}

PALAVRAS-CHAVE: Fluxos Comunicacionais; Circulação; Telejornalismo Local; Materialidade Audiovisual; Brasil em Rede.

ABSTRACT: The objective of this work is to analyze "Brasil em Rede", a television news that presented itself as being local in scope, even though it was broadcast on a regional public broadcaster. The journalistic program was broadcast between December 2017 and January 2019 on Rede Minas, a regional broadcaster in Minas Gerais, and had productions from networked stations throughout Brazil for the news to air daily. As methodology we use the Audiovisual Materiality Analysis (COUTINHO, 2016), which seeks to investigate the audiovisual as a unit and without decomposition and as preliminary results we have the possibility of promoting new looks and voices in Brazilian television journalism in which most national news are produced from the Rio de Janeiro-São Paulo-Brasília axis and the pioneering of a movement inside out of promoting a national news station from a regional broadcaster.

KEYWORDS: Communication Flows; Circulation; Local Television Journalism; Audiovisual Materiality; Brasil em Rede.

\footnotetext{
${ }^{1}$ Doutorando em Comunicação, Mestre e Jornalista formado pela Universidade Federal de Juiz de Fora. Membro do Núcleo de Jornalismo e Audiovisual (NJA-UFJF).

${ }^{2}$ Professora titular da Universidade Federal de Juiz de Fora é jornalista formada pela Universidade Federal do Espírito Santo (1993), mestre em Comunicação e Cultura pela Universidade de Brasília (1999) e doutora em Comunicação Social pela Universidade Metodista de São Paulo (2003)
}

\section{Revista ALTERJOR}

Grupo de Estudos Alterjor: Jornalismo Popular e Alternativo (ECA-USP)

Ano 11 - Volume 02 - Edição 24 - Julho-Dezembro de 2021

Av. Professor Lúcio Martins Rodrigues, 443, Cidade Universitária, São Paulo, CEP: 05508-020 


\section{Rieierer}

Telejornalismo local? Um olhar sobre os processos de globalização e ressignificação do regional na mídia

Devido ao fato de a TV no Brasil se constituir a partir da exploração comercial e com interesses privados, possuindo como principal objetivo o lucro, ela nasce essencialmente direcionada ao nacional e em rede, já que assim alcança o maior número de público possível, reduzindo o telejornalismo regional e local às emissoras afiliadas que ocupam parte da programação televisiva. "Assim, a organização das emissoras de televisão em rede, com a celebração de contratos de afiliação entre estações geradoras, afiliadas e emissoras, é naturalizada no Brasil como se outro modelo de transmissão não existisse" (COUTINHO; EMERIM, 2019, p. 31).

O telejornalismo local foi tema da pesquisa integrada desenvolvida em 2019 pela Rede de Pesquisadores em Telejornalismo (TeleJor). As investigações evidenciaram que na contemporaneidade a definição da abrangência e o local do telejornalismo ultrapassavam a dimensão territorial, com distintas formas de sentimento de pertença com o jornalismo audiovisual.

Ao buscarem definir o telejornalismo local, Coutinho e Emerim (2019) apontam para esse local de busca de representatividade e de identificação do cidadão, que dependeria de vínculos de pertencimento e se efetiva com o reconhecimento do cidadão ao assistir o telejornal. Já Vizeu e Cerqueira (2019) destacam o caráter da proximidade e da maior potencialidade de gerar identidade e representação em relação aos cidadãos.

Neste panorama, propõe-se que tais fluxos comunicacionais que se estabelecem dos conflitos local e nacional sejam relacionados aos processos de globalização, e entendidos como uma das chaves para o início de um movimento de ressignificação dos territórios. A promoção do ideal de uma sociedade global e um mundo sem fronteiras teria surgido como uma resposta aos processos de independência de muitos países na África e na Ásia. Nesse cenário outra resultante da globalização seria um movimento migratório muito significativo, fluxos sobretudo com as antigas metrópoles coloniais, também pela proximidade de língua/idioma, traços e costumes culturais assemelhados. As propostas de redução das diferenças espaciais e de dissolução de fronteiras contaram

Revista ALTERJOR

Grupo de Estudos Alterjor: Jornalismo Popular e Alternativo (ECA-USP)

Ano 11 - Volume 02 - Edição 24 - Julho-Dezembro de 2021 Av. Professor Lúcio Martins Rodrigues, 443, Cidade Universitária, São Paulo, CEP: 05508-020 


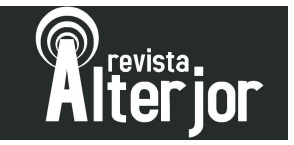

ainda com a popularização da internet; a rede mundial de computadores era vista/ consumida como um espaço online que oferecia a potencialidade de conectar o mundo. As telas, aqui de computadores, aproximariam o distante e proporcionaria um intenso câmbio cultural. Com o movimento de fluxos informativos ampliado em múltiplas plataformas e mídia, havia um processo paralelo de ressignificação do território, hibridização e ressignificação das identidades.

Paradoxalmente, com a quebra das barreiras e fronteiras, aqui hertzianas, do telejornalismo local, observamos um processo de revalorização e ressignificação do local. O telejornalismo local teria a questão territorial como ponto de partida ou referente originário, mas um novo localismo surgiria da partilha de identidades, da produção simbólica de pertencimento(s) entre emissora e públicos. O geógrafo Rogério Haesbaert (1999) sugere que a globalização deve ser pensada de forma conjunta com a regionalização, e os fluxos globais teriam produzido uma redefinição nas escalas da diversidade territorial. A mídia e o telejornalismo em particular participariam desse redesenho de escala.

A mídia também alimenta uma revalorização do "regional", ainda que ele seja entendido de maneiras as mais diversas. Para alguns, uma nova valorização do regional aparece no próprio bojo da globalização dos mercados e das comunicações, o regional aí sendo interpretado como uma revalorização do singular, da diferença; para outros, a nova "regionalização" seria um contraponto à globalização, via criação de grandes uniões comerciais - como se os mercados comuns não estivessem inseridos numa articulação crescente aos circuitos globais da economia capitalista (HAESBAERT, 1999, p. 16).

A partir disso, Haesbaert (1999) aponta para uma redefinição da região, que estaria muito ligada as relações entre os níveis local e global. O autor menciona a emergência de regiões numa nova escala regional, eventualmente com o surgimento dos "Estadosregiões", estabelecidas em um território econômico e descoladas da geografia política. Esse apagamento de fronteiras seria fertilizado pelos fluxos, audiovisuais inclusive, potencializado pela circulação na web, com destaque nesse texto para aquela de cunho (tele)jornalístico. Junto aos processos de (des)territorialização haveria um esforço por ressignificar o território, e aqui ressaltamos as buscas por construção desses laços nos atos

\section{Revista ALTERJOR}

Grupo de Estudos Alterjor: Jornalismo Popular e Alternativo (ECA-USP)

Ano 11 - Volume 02 - Edição 24 - Julho-Dezembro de 2021 Av. Professor Lúcio Martins Rodrigues, 443, Cidade Universitária, São Paulo, CEP: 05508-020 


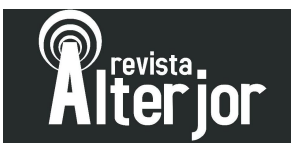

de discurso e informação do telejornalismo, como naqueles em direção ao alcance da audiência presumida conceituada por Vizeu (2005).

Nessas novas percepções de território haveria dois movimentos e processos. Um movimento seria dos grupos privilegiados economicamente, com mais acesso a trocas e à sociedade global e corresponderia à processos de constituição de territórios de caráter complexo, múltiplo, híbrido e flexível. O segundo movimento atingiria grande parcela da sociedade, e envolveria pessoas que não tem acesso ao consumo amplo e eficiente da e que portanto habitariam zonas de sombra e silêncio; sem sequer possuir seu próprio território, esta parcela da(s) sociedade(s) precisaria se submeter utilizar parte do território do outro, descrito por Haesbaert (1999) como um espaço mais inflexível e fechado, com marcas da separação entre pobres e ricos, entre conectados e desconectados (Canclini, 2007). Excluídos do exercício amplo do ciberespaço, desconectados experimentariam uma revalorização dos vínculos com o território físico e material. A revalorização do local/regional como lugar de identificação e de representação ocorreria principalmente a partir da oferta dos meios de comunicação de massa, entre os quais coloca-se em relevo nesse texto a televisão, e os telejornais em particular.

Ao tratar do audiovisual, e mais especificamente da TV, Moreira e Del Bianco (2018) registram a existência de zonas de sombra e silêncio, regiões que sem serviços de rádio e televisão, dificilmente são representadas na mídia; a comunicação dessas localidades não ultrapassa o local. "Embora o acesso à internet tenha superado fronteiras, saindo do espaço urbano para o rural, no caso do Brasil uma parcela expressiva da população está fora desse espaço virtual” (MOREIRA; DEL BIANCO, 2018, p. 7). As autoras ainda mencionam a carência de pesquisas nas pequenas cidades brasileiras, com população entre 500 e 100 mil habitantes.

O reconhecimento da existência dessas zonas de sombra e silêncio é a chave nesse texto para o estudo do programa Brasil em Rede, noticiário de caráter nacional produzido e veiculado pela Rede Minas. A partir da análise da materialidade audiovisual, buscaremos entender como em sua experiência informativa o telejornal construiu os sentidos de local e nacional, se o conflito local-global é dado a ver nas narrativas

\section{Revista ALTERJOR}

Grupo de Estudos Alterjor: Jornalismo Popular e Alternativo (ECA-USP)

Ano 11 - Volume 02 - Edição 24 - Julho-Dezembro de 2021 Av. Professor Lúcio Martins Rodrigues, 443, Cidade Universitária, São Paulo, CEP: 05508-020 


\section{Pereijor}

telejornalísticas do programa e se ele é capaz de representar e tornar visíveis locais e personagens que estariam à margem ou sombra.

\section{Brasil em Rede e mineiridade: do local ao nacional-global}

Ao abordar o fenômeno da globalização, Martín-Barbero (2004) aponta para um fluxo local x global(ização) que tinha como objetivo a mundialização da cultura e a reconfiguração do sentido de cidadania, muito ancorado na quebra e queda das fronteiras e de um cidadão mundial, e com isso, destaca uma redefinição da ideia de nação e em uma redefinição da relação centro/periferia. A partir do contexto da América Latina, Jesús Martín-Barbero trabalha com uma relação de dualidade dada pela abertura nacional para o globo, ou seja, um processo de transnacionalização, e ao mesmo tempo para uma maior integração regional, que leva a uma revalorização do local/regional.

Para entender a experiência do Brasil em Rede na emissora pública de televisão de Minas Gerais, a Rede Minas, é preciso antes abordar e compreender a mineiridade como valor, antes cultural que simbólico. A hipótese é que a demanda por tirar da sombra ou invisibilidade audiovisual se refletiria na oferta do noticiário nacional que durante cerca de 13 meses foi produzido e veiculado em uma emissora de televisão de alcance estadual. Minas Gerais começa a se constituir em 1720, inicialmente como uma capitania separada de São Paulo, e posteriormente como um estado da nação Brasil. Desde o início com seu surgimento ligado ao trabalho dos bandeirantes de diversas localidades em busca de ouro e pedras preciosas, as Minas Gerais já nasceram múltiplas, diversas e plurais, sendo uma mistura de culturas. Ao longo do tempo, Minas Gerais passou também a ser um polo da cafeicultura brasileira, e devido à expansão dessa atividade e à economia forte, o estado passou a acolher também o setor industrial, o que culminou em uma sociedade miscigenada.

Entretanto, ainda que Minas Gerais assuma várias identidades e formas de ser representado, o estado também encontra na "mineiridade" uma forma de unificar o "jeito mineiro de ser" e a forma em que o mineiro é representado. A palavra mineiridade é descrita nos dicionários como qualidade, condição ou atitude do mineiro. Nesse sentido,

\section{Revista ALTERJOR}

Grupo de Estudos Alterjor: Jornalismo Popular e Alternativo (ECA-USP)

Ano 11 - Volume 02 - Edição 24 - Julho-Dezembro de 2021 Av. Professor Lúcio Martins Rodrigues, 443, Cidade Universitária, São Paulo, CEP: 05508-020 


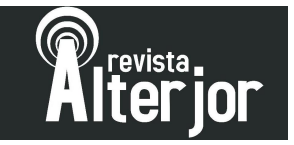

trabalharemos no presente trabalho não apenas com uma mineiridade, mas sim com "mineiridades", já que temos muitas Minas Gerais e diversas formas de identificação acerca do ser mineiro. Recorremos a uma imersão na literatura para compreendermos o ser mineiro e a mineiridade na ótica de alguns escritores. A primeira referência é João Guimarães Rosa ${ }^{3}$, autor de clássicos da literatura nacional como Grande Sertão Veredas. A palavra mineiridade surge em texto de agosto de 1957 intitulado "Aí está Minas: mineiridade"4 e que retrata várias faces e particularidades das muitas Minas Gerais, bem como características dos vários tipos de mineiros. Em Grande Sertão Veredas, João Guimarães Rosa busca trazer a mineiridade ligada à integração da atividade de mineração com a pecuária; Minas Gerais é representada a partir de visão interiorana.

João Batista Queiroz também trata da questão da Mineiridade no poema intitulado "Ser Mineiro", em que busca retratar uma imagem de mineiro do interior, com características típicas como desconfiança, simplicidade, apreço à natureza e religião. Além disso, Queiroz também aborda a questão geográfica de Minas Gerais ligada ao interior (do país) e seu relevo montanhoso, o que também remete a um ambiente intimista e acolhedor.

Um terceiro escritor com relação íntima com Minas Gerais em suas obras é Carlos Drummond de Andrade. Nascido em Itabira e com formação em Belo Horizonte, em vários momentos o autor trabalha sua mineiridade baseada em lembranças de sua infância, atrelada às mudanças que o estado passava na segunda metade do século XX.

O poema "Confidência do Itabirano" (Drummond, 1973, pp. 101-2) é exemplar, precisamente, do motivo pelo qual o sujeito drummondiano não se liberta do chão da sua história, do seu lugar originário, não se converte numa abstração transcendental entregando-se pura e simplesmente ao pensamento. A cidade - o poeta nos mostra - não constitui uma instância exterior ao sujeito,

\footnotetext{
${ }^{3}$ Nascido em Cordisburgo, Minas Gerais, no ano de 1908, Guimarães Rosa morou em Belo Horizonte e em São João Del Rei durante seus estudos e formação.

${ }^{4}$ Texto publicado na revista "O Cruzeiro"

${ }^{5}$ Poesia registrada em 22/03/1985, sob o número 33702, na Biblioteca Nacional do Rio de Janeiro
}

\section{Revista ALTERJOR}

Grupo de Estudos Alterjor: Jornalismo Popular e Alternativo (ECA-USP)

Ano 11 - Volume 02 - Edição 24 - Julho-Dezembro de 2021 Av. Professor Lúcio Martins Rodrigues, 443, Cidade Universitária, São Paulo, CEP: 05508-020 


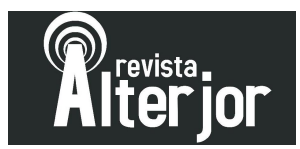

mas integra, sim, o próprio sujeito, é parte de sua interioridade, estrutura, portanto, sua identidade, é uma realidade, não uma idealidade (OLIVEIRA, 2017, p. 162).

De acordo com o autor, a poesia de Carlos Drummond teria a marca do barroco, dos tensionamentos entre Minas Gerais e Brasil, local e nacional. Da literatura à mídia televisiva, Simone Maria Rocha, busca analisar a mineiridade a partir de duas perspectivas: da formação de identidades, que passam pela ideia de nação, região e sentimento de pertença; e da imagem do mineiro que é construída pela mídia, muitas vezes com um tom humorístico e com uma imagem estereotipada do que é mineiridade. Ao trabalhar com o discurso da mineiridade como identidade regional na televisão, Rocha (2003) buscou entender como se organizam os conteúdos produzidos pela TV acerca dos mineiros e como era a recepção desse material. De acordo com o estudo, a mineiridade seria narrada e apropriada de maneira diversa conforme a região cultural do estado. Mas, apesar da existência de várias regiões culturais, há segundo a autora características que unem todas essas regiões acerca do sentimento de mineiridade. Até mesmo o conteúdo midiático produzido sobre o "mineiro puro", ligado a tradições rurais e ao período colonial, mesmo que em representação estereotipada auxiliaria na legitimação da mineiridade.

Quando fazíamos as sessões de vídeo, embora tenha havido alguma exceção, a maioria das pessoas confirma que as personagens representam "o mineiro" de alguma forma. Em alguns casos eles alegaram a ridicularização, em outros consideram apenas o mineiro da zona rural, o "mineiro puro", mas em geral, pudemos perceber que o estereótipo atua num plano comunicacional de maneira positiva. Ele confirma alguns valores, alguns traços que já fazem parte do imaginário social (ROCHA, 2003, p. 11).

A partir da revisão bibliográfica sobre os sentidos de mineiridade, inclusive em diálogo com o audiovisual, buscamos entender a proposta nacional do Brasil em Rede como uma potencialidade de representação mais múltipla de muitas "Minas Gerais". Em termos geográficos o estado faz divisa com três regiões e seis estados do Brasil: Espírito Santo, Rio de Janeiro e São Paulo, na região Sudeste; Mato Grosso do Sul, Goiás e Distrito Federal, na região

\section{Revista ALTERJOR}

Grupo de Estudos Alterjor: Jornalismo Popular e Alternativo (ECA-USP)

Ano 11 - Volume 02 - Edição 24 - Julho-Dezembro de 2021 Av. Professor Lúcio Martins Rodrigues, 443, Cidade Universitária, São Paulo, CEP: 05508-020 


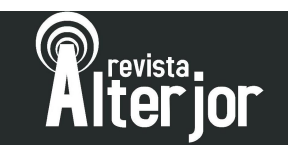

Centro-Oeste; e Bahia da região Nordeste. Assim há diferentes fronteiras, inclusive culturais, e de sotaques.

\section{A oferta de conteúdo nacional na emissora de TV pública de Minas Gerais}

Nesse trabalho tomamos as narrativas da mineiridade e suas formas de representação como chave interpretativa para o estudo do programa Brasil em Rede. Telejornal produzido da Rede Minas, emissora de TV cujo alcance sequer abarca todo o estado de Minas Gerais, durante um ano e um mês ofereceu um noticiário de caráter e conteúdo nacional, embora transmitido via televisão apenas regionalmente. E se tanto pesquisadores quanto profissionais do mercado destacam a necessidade de (re)conhecer não apenas o programa, mas a programação ao abordar a comunicação televisiva, aqui de caráter jornalístico, torna-se importante conhecer a emissora de televisão pública do estado de Minas Gerais.

Criada em dezembro de 1984, por Tancredo Neves, a Rede Minas se intitula uma emissora pública e educativa, que tem o objetivo de "potencializar o intercâmbio de valores, educação e cultura para a população, por meio da produção e veiculação de programas de televisão de interesse público." (SITE DA REDE MINAS, 2018). A emissora transmite sua programação 24 horas por dia em seu site e também nas suas páginas em redes sociais digitais como Facebook e Youtube. A Rede Minas em seu site afirma estar presente em mais de 765, dos 853 municípios do estado de Minas Gerais, embora não explicite como essa presença se materializaria. O espaço institucional digital ainda aponta a missão da emissora de enriquecer a vida das pessoas com produções informativas, culturais e educativas e seus valores como empresa: "família; pertencimento; interesse público; isenção; transparência; cidadania; pluralidade; diversidade; e cultura mineira" (SITE DA REDE MINAS, 2018).

A produção jornalística própria da Rede Minas conta com dois telejornais regionais diários em sua grade de programação: o Minas em Rede, produzido de forma colaborativa entre emissoras de TV parceiras nas várias regiões do Estado, e o Jornal Minas, com maior enfoque territorial e de realização na capital Belo Horizonte, sede da emissora. A esses dois telejornais de produção própria somou-se o programa Brasil em

\section{Revista ALTERJOR}

Grupo de Estudos Alterjor: Jornalismo Popular e Alternativo (ECA-USP)

Ano 11 - Volume 02 - Edição 24 - Julho-Dezembro de 2021 Av. Professor Lúcio Martins Rodrigues, 443, Cidade Universitária, São Paulo, CEP: 05508-020 


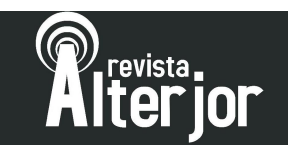

Rede, foco desse estudo, veiculado entre os dias 11 de dezembro de 2017 e o dia 03 de janeiro de 2019. O terceiro telejornal produzido pela Rede Minas tinha como principal diferencial a proposta de apresentar um conteúdo e relato nacionais em uma emissora regional de TV. Tomou-se a experiência diferenciada do programa como pretexto para compreender as formas do telejornalismo representar o nacional e o local. Transmitido de segunda à sábado, às 20h15m, o Brasil em Rede tinha duração de 30 minutos e apresentação de Raquel Capanema e Luciano Correia. A Rede Minas apresentava o telejornal como:

Primeiro telejornal de notícias nacionais produzidas em MG com cobertura dos fatos de maior impacto em todo o Brasil. Direto da nova e moderna newsroom, conteúdos diferenciados e com credibilidade sobre economia, política, saúde, prestação de serviços e cultura. Colaborativo, conta com a parceria de emissoras de todas as regiões do país. Jornalismo com mais tecnologia e comunicação pública fortalecida (SITE DA REDE MINAS, 2019).

Para compreender a experiência do programa, e as formas de representação do nacional em uma emissora com a marca da mineiridade em seu DNA, tomou-se como método a análise da materialidade audiovisual proposto por Iluska Coutinho (2016).

\section{Os fluxos informativos no jornalismo audiovisual do Brasil em Rede}

A proposta central do método é de analisar os conteúdos audiovisuais a partir das complexidades implicadas na unidade "texto + som + imagem + tempo + edição" sem recorrer à decomposição de códigos de linguagem e narrativas constitutivas do produto e experiências telejornalísticas(COUTINHO, 2016, p. 10). Para realizar a análise da materialidade audiovisual, após reflexão conceitual via pesquisa bibliográfica, o segundo passo seria o estabelecimento de eixos de análise que vão nortear a investigação do objeto de investigação, dois no caso do presente trabalho. Assim, considerando os fluxos de comunicação locais, globais e nacionais, e sua interface com a proposta diferenciada do programa tomado como objeto, o primeiro eixo a ser observado é o da relação localglobal.

\section{Revista ALTERJOR}

Grupo de Estudos Alterjor: Jornalismo Popular e Alternativo (ECA-USP)

Ano 11 - Volume 02 - Edição 24 - Julho-Dezembro de 2021 Av. Professor Lúcio Martins Rodrigues, 443, Cidade Universitária, São Paulo, CEP: 05508-020 


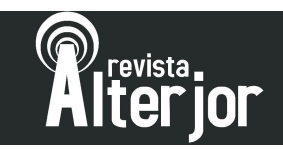

Coloca-se em tensionamento o fato de o Brasil em Rede ter sido produzido no âmbito e estrutura/ raio de atuação de uma emissora de televisão local. Em um primeiro momento o alcance do sinal de transmissão televisiva poderia restringir a oferta dos conteúdos ao caráter regional da emissora, em termos territoriais. Contudo, ao disponibilizar ao vivo sua programação por meio de sua página na web e em redes sociais digitais, a emissora implodiria essa fronteira ou lógica territorial; uma produção local assim busca apresentar um conteúdo expandido para o nacional, que poderia ser experimentado globalmente em múltiplas telas e fluxos. A identidade da emissora e do relato, calcado na mineiridade, seria tecido assim por relações de pertencimento de caráter mais simbólico que geográfico. Um exemplo disso é observado nas fontes do telejornal em produções que não são de emissoras parcerias, em que mesmo em assuntos de caráter nacional busca-se especialistas ou populares de Minas Gerais, e mais especificamente de Belo Horizonte, cidade em que o programa era produzido.

Imagem 1: Edição do dia 24 de abril de 2018 do Brasil em Rede

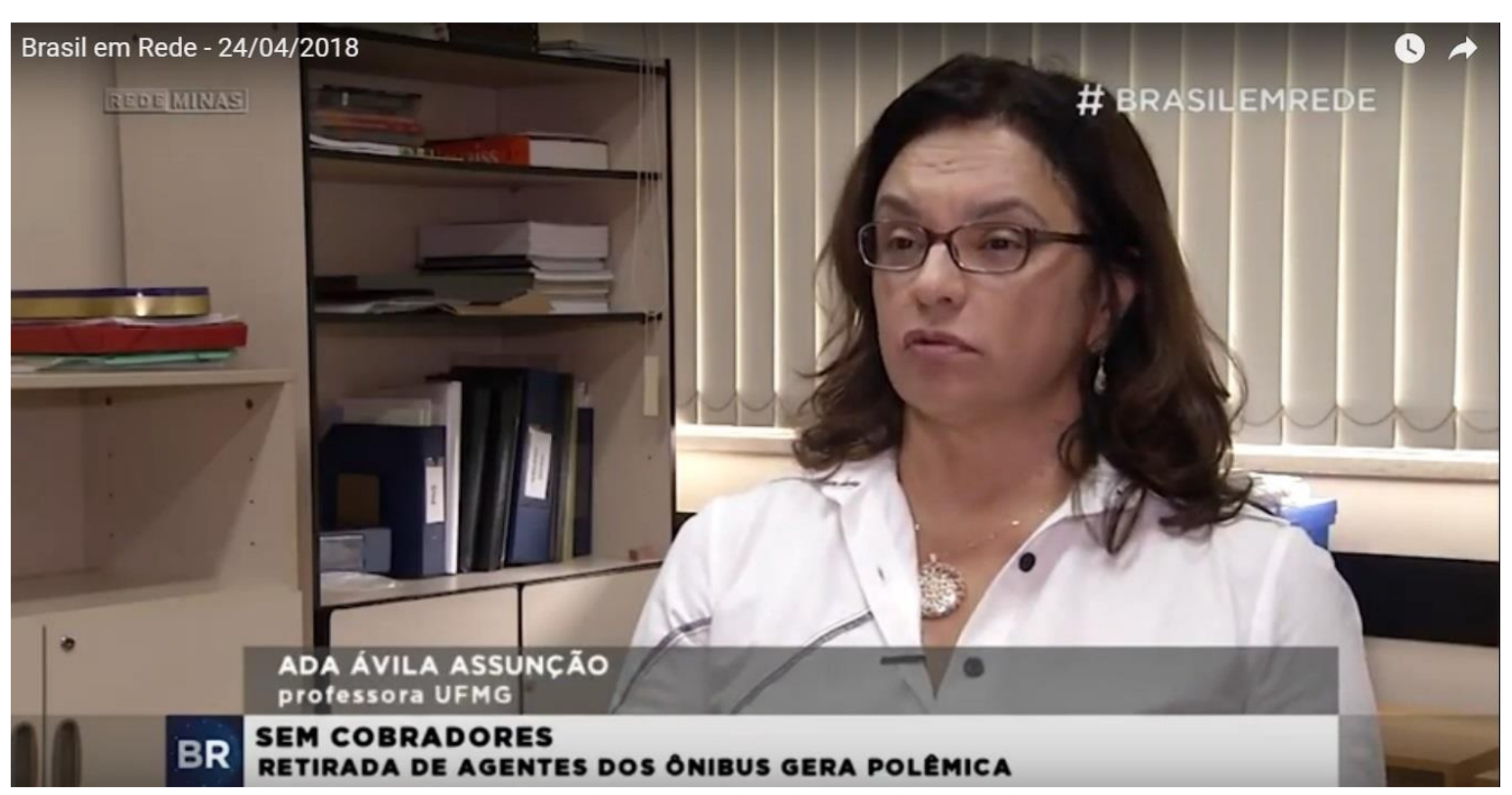

Fonte: Canal no Youtube do Brasil em Rede.

Assim, ainda que o ambiente online contribua para a experiência do local e do nacional por meio de telas e cenários cada vez mais globalizados e conectados, observou-

\section{Revista ALTERJOR}

Grupo de Estudos Alterjor: Jornalismo Popular e Alternativo (ECA-USP)

Ano 11 - Volume 02 - Edição 24 - Julho-Dezembro de 2021 Av. Professor Lúcio Martins Rodrigues, 443, Cidade Universitária, São Paulo, CEP: 05508-020 


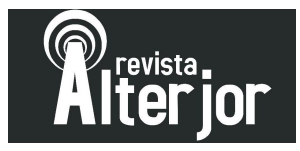

se que as fontes essencialmente eram locais, ainda que a pauta fosse nacional, destacando esse outro lugar de fala do Brasil em Rede.

O segundo eixo de análise relaciona-se com o alcance da experiência localnacional por meio de uma narrativa telejornalística que se propaga por meio internet. Esse ambiente de fluxos expandidos globalmente também contribuiria para a propagação de culturas locais, para a experiência de proximidade por meio do contato com programas como o Brasil em Rede que dialoga com os telespectadores localizados no Estado, com aqueles que não estão no estado de Minas mas ainda guardam simbolicamente sua origem e características da mineiridade, e ainda para um outro público potencial, que mesmo tendo pouco ou nenhum contato com a cultura mineira, poderia se familiarizar com a forma de representação da mineiridade, em uma narrativa nacional.

Para compreender a natureza dessas experiências e mesmo da proposta do programa é importante recorrer a Thussu (2007), que busca entender os fluxos comunicacionais a partir de três categorias : global, transnacional e geo-cultural. $\mathrm{O}$ autor observa o aumento dos fluxos de mídia nas direções Norte-Sul, Leste-Oeste e Sul-Sul, com enfoque na mídia audiovisual e um movimento que denomina "Glocalização", quando mensagens globais se associariam a locais produzindo um contra-fluxo em relação ao fluxo dominante, que tensionariam. Thussu ainda aponta uma tendência de crescimento regional ou local dos conteúdos periféricos, e uma ressignificação das identidades, com a valorização de culturas antes desconhecidas (periféricas), mas que agora se tornam visíveis graças a comunicação em rede.

Mais que caracterizar-se como um contrafluxo, o Brasil em Rede estaria no âmbito geo-cultural, e buscaria incluir e aproximar os distantes. Isso pode ser percebido nas narrativas e conteúdos que apesar de se darem a ver, serem enunciados como nacionais e por vezes até globais, guardariam características muito próximas com Minas Gerais e com a mineiridade, aqui entendida como forma de identidade cultural, associada a um grupo, não limitada territorialmente. Ao reduzir a escala da análise de Thussu, e considerar como foco o âmbito nacional (brasileiro), o Brasil em Rede pode ser considerado um telejornal translocal, já que se configura como um contra-fluxo muito claro em relação à produção

\section{Revista ALTERJOR}

Grupo de Estudos Alterjor: Jornalismo Popular e Alternativo (ECA-USP)

Ano 11 - Volume 02 - Edição 24 - Julho-Dezembro de 2021 Av. Professor Lúcio Martins Rodrigues, 443, Cidade Universitária, São Paulo, CEP: 05508-020 


\section{Preiejer}

apresentada no telejornalismo veiculado em rede, centrado no eixo Rio-São PauloBrasília, regiões que concentram os conteúdos dominantes.

Assim, a experiência do programa pode ser considerada um contraponto ou alternativa aos telejornais nacionais apresentados pelas emissoras afiliadas à redes de televisão, em que há diversas regiões ocultas ou localizadas em zonas de sombra e silêncio. São espaços e locais que tornam-se presentes em geral apenas pela perspectiva do inusitado e/ou da transgressão, com ocorrência de fato capaz de reunir valores-notícias capazes de romper com as barreiras e isolamentos, aqui geográficos mas também simbólicos. Essa busca por maior representação de diferentes locais na narrativa nacional incluiria o estado de Minas Gerais, que apesar da proximidade territorial com os centros do jornalismo audiovisual brasileiro, acaba sendo silenciado do pluralismo das muitas Minas existentes.

Esse silenciamento foi evidenciado em estudo realizado anteriormente no âmbito do Núcleo de Jornalismo e Audiovisual, em que buscamos comparar a presença de notícias de ou sobre Minas Gerais em dois telejornais nacionais: Jornal Nacional (Rede Globo) e o Repórter Brasil (TV Brasil). Tomando como recorte duas semanas de cada telejornal. Na ocasião foram analisadas as semanas de 26 de março a 01 de abril de 2018 , que inclui o período da páscoa em que poderia aflorar a representação da mineiridade, religiosa, e de 23 à 29 de abril, que permitiria a observação de período sem nenhum fato típico. A proposta da investigação então realizada era compreender o espaço e a representação da identidade mineira em rede nacional também pela presença de matérias realizadas no estado de Minas e de sua frequência e incidência delas nos telejornais analisados.

No recorte empírico investigado identificou-se que das 117 matérias veiculadas no período pelo Repórter Brasil, apenas três eram ou tinham algum vínculo com Minas Gerais, índice equivalente a aproximadamente $2 \%$ do conteúdo exibido no programa. No Jornal Nacional, oito entre 214 matérias editadas no período foram sobre Minas Gerais ou sobre alguma personalidade notadamente mineira, cerca de $3,5 \%$ da materialidade audiovisual realizada. Ao comparar essa representação ao noticiário Brasil em Rede,

\section{Revista ALTERJOR}

Grupo de Estudos Alterjor: Jornalismo Popular e Alternativo (ECA-USP)

Ano 11 - Volume 02 - Edição 24 - Julho-Dezembro de 2021 Av. Professor Lúcio Martins Rodrigues, 443, Cidade Universitária, São Paulo, CEP: 05508-020 


\section{Anteier}

temos que 16 das 141 matérias presentes no telejornal nos períodos analisados possuíam algum vínculo com Minas Gerais e/ou com a mineiridade. O percentual de 11,3\% do conteúdo total ainda assim é considerado baixo, sobretudo pela circunstância de realização do programa, mas que mais de três vezes superior à presença nos outros telejornais analisados.

Aprofundando a análise do noticiário nacional do Brasil em Rede, percebemos na análise a emergência de fontes de informação de Minas Gerais como diferencial do telejornal nacional, produzido e veiculado em uma emissora regional de TV. Ainda que contingencial, resultado até de carências de equipe e recursos, em várias das matérias investigadas é possível observar entrevistas, povo fala ou mesmo angulações de matérias que são de âmbito global ou nacional, mas cuja materialidade audiovisual tem cenário, rosto e personagens localizados em Minas Gerais. O produto jornalístico resultante, embora enunciado como nacional, apresenta- se assim como um telejornal mais próximo do Estado e de seus cidadãos, com maior representatividade, mais presença do que compreendemos a partir dos autores referência nesse texto como mineiridade.

A revalorização do local emerge como resultado importante na compreensão do contra-fluxo nacional produzido pelo Brasil em Rede. Até por conta da falta de equipe e de recursos, em várias das matérias investigadas é possível observar entrevistas, povo fala ou mesmo angulações de matérias que são de âmbito global ou nacional, mas que é produzida em Minas Gerais, dando um caráter mais próximo e representativo do estado e de seus cidadãos. Com isso, a revalorização do local se faz essencial para a compreensão do contra-fluxo produzido pelo Brasil em Rede, como na matéria sobre a Paixão de Cristo, que é produzida no município de Caeté-MG.

Revista ALTERJOR

Grupo de Estudos Alterjor: Jornalismo Popular e Alternativo (ECA-USP)

Ano 11 - Volume 02 - Edição 24 - Julho-Dezembro de 2021 Av. Professor Lúcio Martins Rodrigues, 443, Cidade Universitária, São Paulo, CEP: 05508-020 


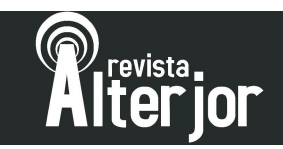

Imagem 2: Edição do dia 30 de março de 2018 do Brasil em Rede

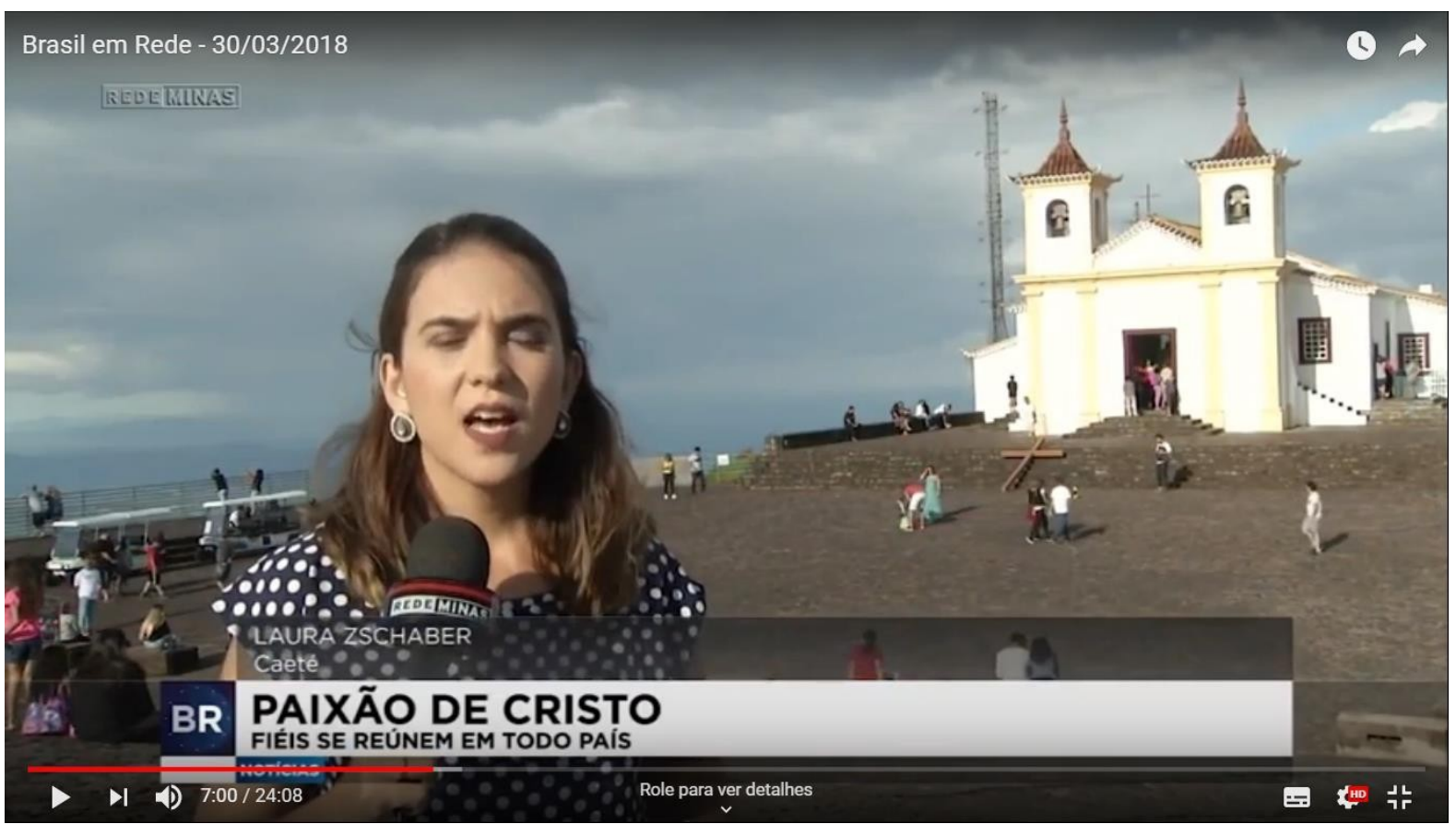

Fonte: Canal no Youtube do Brasil em Rede

Nesses fluxos diversos representados e apresentados pelo programa ganham destaque as parcerias feitas entre o telejornal e outras emissoras. Estas também estariam em zonas de sombra com uma representação ainda menor nos principais telejornais das redes nacionais de televisão, e se associariam ao contra-fluxo realizado pela emissora pública mineira eventualmente como estratégia para ampliação de sua visibilidade, telejornalística.

Assim, apesar de produzido e editado a partir de Minas Gerais, o Brasil em Rede apresenta-se como uma produção de caráter nacional que é construída a partir da busca pelo diverso, com conteúdos que apresentam representatividade ao colocar em cena diferentes lugares de fala, com a manutenção das características locais dessas produções, exibidas na rede mineira de televisão, e digitalmente para além das fronteiras e fluxos locais. Nas duas semanas analisadas foi possível perceber matérias com cenários, personagens, representação de Sergipe, Amazonas, Tocantins, Roraima, Paraná e ainda oferta de conteúdos internacionais.

\section{Revista ALTERJOR}

Grupo de Estudos Alterjor: Jornalismo Popular e Alternativo (ECA-USP)

Ano 11 - Volume 02 - Edição 24 - Julho-Dezembro de 2021 Av. Professor Lúcio Martins Rodrigues, 443, Cidade Universitária, São Paulo, CEP: 05508-020 


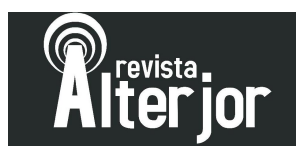

Ao promover parcerias com emissoras de outros estados, o Brasil em Rede consegue não apenas criar materiais de caráter nacional, pela ampliação da área de cobertura do telejornal, como também valoriza o local, já que os vários locais tem liberdade para produzir pautas que possam trazer assuntos nacionais, mas com uma representação local, que se dá através das manifestações culturais, cenário, sotaque, entre outras características, como na matéria sobre ajuda aos refugiados na cidade de Boa Vista, produzida pela TV Universitária de Roraima.

\section{Imagem 3: Edição do dia 23 de abril de 2018 do Brasil em Rede}

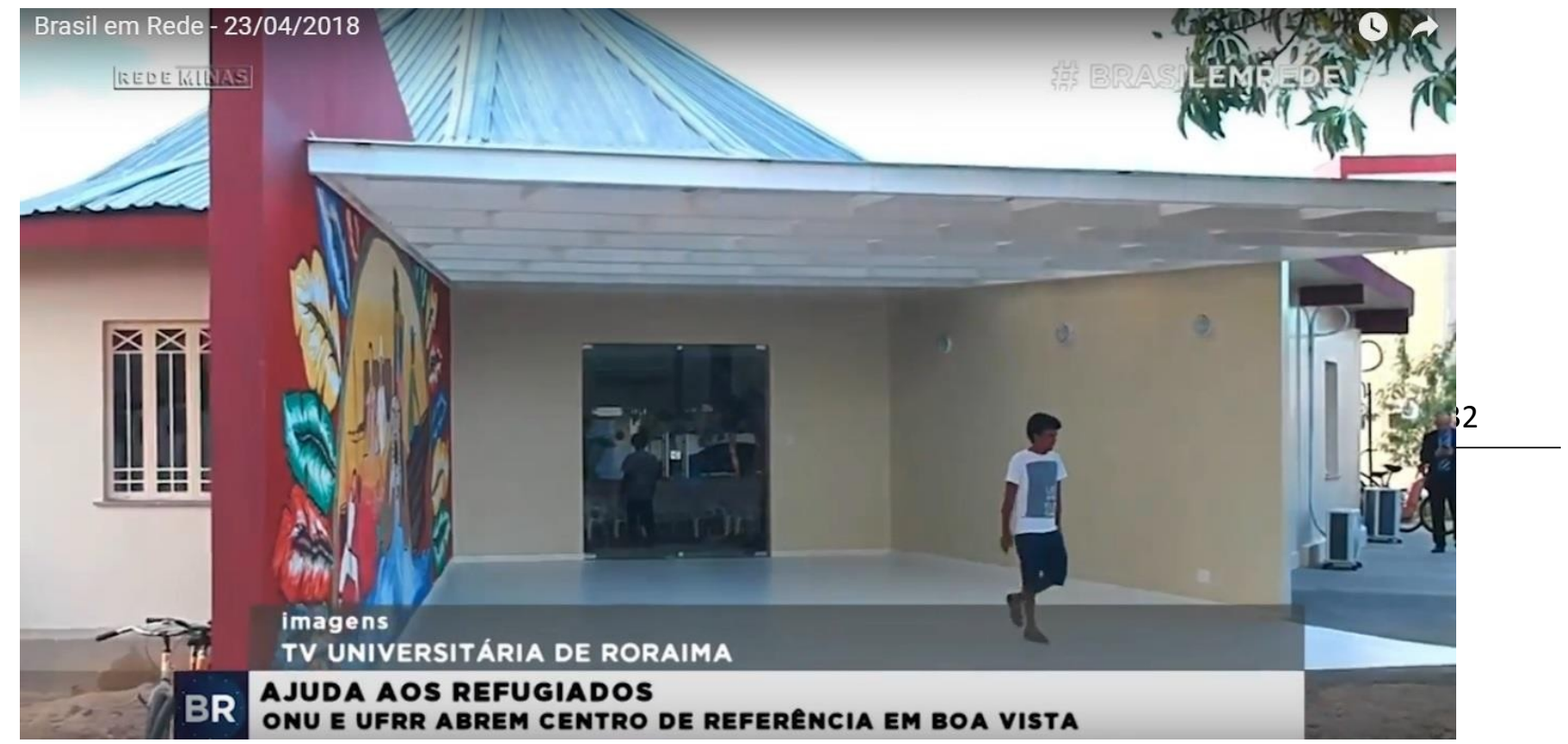

Fonte: Canal no Youtube do Brasil em Rede

O programa, em paralelo, reforça a mineiridade e o acesso a novas culturas e identidades locais, quer no âmbito regional da transmissão televisiva mineira e/ou global via redes sociais digitais.

Também merece destaque na análise o par Territorialização/Desterritorialização. Com uma narrativa mais ampla que seu território/lugar de fala, o Brasil em Rede consegue ampliar o alcance de Minas Gerais por meio dessas parcerias, e re-significa a identidade nacional. No noticiário analisado, a janela que se dá a ver é diversa daquela comumente

\section{Revista ALTERJOR}

Grupo de Estudos Alterjor: Jornalismo Popular e Alternativo (ECA-USP)

Ano 11 - Volume 02 - Edição 24 - Julho-Dezembro de 2021 Av. Professor Lúcio Martins Rodrigues, 443, Cidade Universitária, São Paulo, CEP: 05508-020 


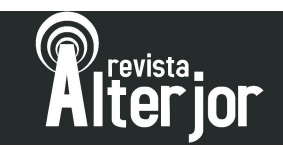

observada nos principais telejornais nacionais, porque está ancorada no relato local e não naquele produzido para a rede.

Imagem 4: Edição do dia 28 de abril de 2018 do Brasil em Rede

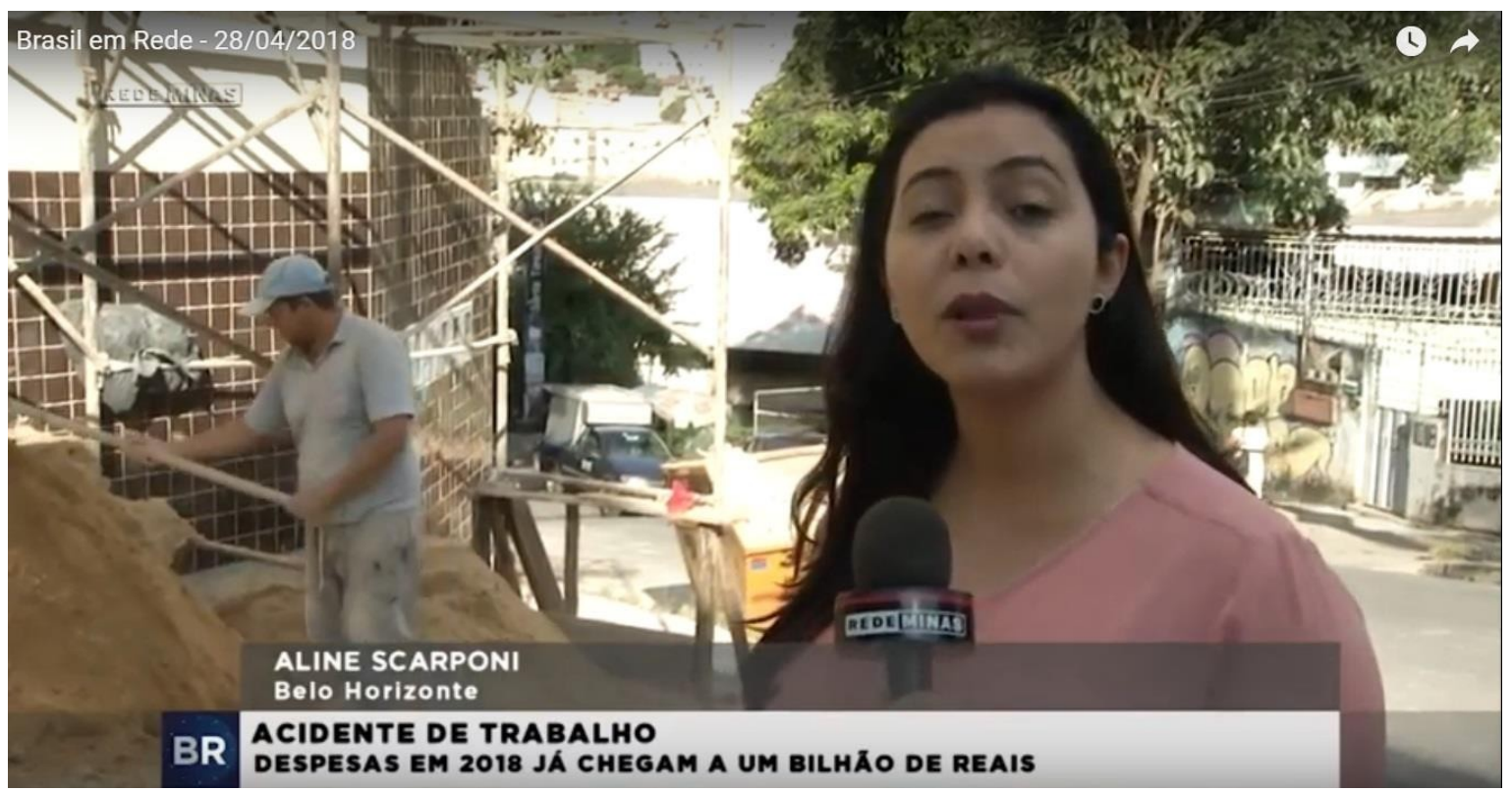

Fonte: Canal no Youtube do Brasil em Rede

A importância do território Minas Gerais permite que a mineiridade esteja mais presente na experiência do Brasil em Rede, reforçando os laços de pertencimento com os mineiros, em uma identidade que ultrapassaria fronteiras espaciais. A agenda noticiosa também é diversa; Minas Gerais e a capital Belo Horizonte assumem um lugar de fala e referência no telejornal. Há diálogos com conteúdos de outras emissoras locais e até independentes que por meio da narrativa do (tele)jornalismo público conquistariam representação e visibilidade nas edições do Brasil em Rede.

\section{Considerações Finais}

Partindo de sua proposta inicial, observa-se que o Brasil em Rede produz um movimento contrário àquele que normalmente busca-se produzir no telejornalismo brasileiro, que é transmitir as informações dos fluxos nacional/global para o local/regional. No programa analisado temos fluxos locais e regionais que alcançam por

\section{Revista ALTERJOR}

Grupo de Estudos Alterjor: Jornalismo Popular e Alternativo (ECA-USP)

Ano 11 - Volume 02 - Edição 24 - Julho-Dezembro de 2021 


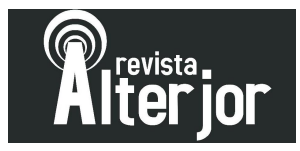

meio do noticiário da Rede Minas um status ou notoriedade nacionais e mesmo globais, considerando que a presença do jornalismo audiovisual em circulações possibilitadas via utilização da internet amplia potencialmente o alcance do sinal televisivo da emissora pública mineira.

Para a compreensão da proposta e experiência, ainda que breve desse telejornal nacional criado em uma emissora regional, foi importante resgatar o conceito de mineiridade. $\mathrm{O}$ apreço à tradição, a habilidade de conversa, o ser mineiro configura-se como estratégia para oferecer uma janela alternativa aos noticiários de alcance nacional, centrados no eixo Rio-São Paulo-Brasília. Pela programação da emissora pública mineira, acessada em múltiplas telas, não só Minas Gerais, mas outras localidades de parceiras, tem-se sem ruptura ou conflito, o acesso a outros telejornalismo locais, experimentados de forma particular em uma narrativa brasileira que acaba por contrapor às zonas de sombra evidenciadas por estudiosas da radiodifusão tomados como referência nesse texto.

A estratégia que surgiu mineiramente, sem alarde, poderia ser assim entendida como uma espécie de contra-fluxo a outros telejornais exibidos em rede nacional, ancorados no tripé do poder político-econômico e simbólico de Rio-São Paulo-Brasília. Nesse sentido o Brasil em Rede configurou-se durante pouco mais de um ano como uma opção para oferta de um conteúdo nacional a partir de um outro olhar, o mineiro, e de forma mais específica do mineiro de Belo Horizonte, capital do Estado e sede da Rede Minas. O noticiário apresentou como potencialidade a perspectiva de que seria possível produzir uma outra narrativa, ancorada a partir do local, com cenários e fontes diversos daquela tornada realidade na agenda noticiosa do jornalismo televisivo ofertado nas redes de televisão nacionais, de exploração comercial. Se os fluxos comunicacionais contemporâneos são ampliados e convergentes, o Brasil em Rede apresenta narrativas que não se limitam ao espaço físico e territorial ou ao circuito local de cobertura, mas são expandidas em parcerias que exibem diferentes locais e um nacional mais diverso.

Consideramos que essa experiência aponta questões importantes na reflexão sobre o lugar do telejornalismo local e nacional no cenário brasileiro, ainda que a duração do programa tenha sido de pouco mais de um ano. Isso é reforçado pelo Brasil em Rede ter

\section{Revista ALTERJOR}

Grupo de Estudos Alterjor: Jornalismo Popular e Alternativo (ECA-USP)

Ano 11 - Volume 02 - Edição 24 - Julho-Dezembro de 2021 Av. Professor Lúcio Martins Rodrigues, 443, Cidade Universitária, São Paulo, CEP: 05508-020 


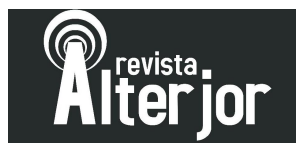

se constituído por um movimento pioneiro, e em certa medida contra- hegemônico, no que diz respeito à readequação do telejornalismo às multi-telas; a internet se tornou um espaço importante tanto para a produção, por meio de trocas de conteúdo jornalístico audiovisual entre emissoras parceiras, quanto para a fruição do Brasil em Rede, em laços de pertencimento da mineiridade construído via experiência noticiosa.

Por meio do programa Brasil em Rede, as dimensões e personagens Local/Regional acabam se relacionando diretamente com o âmbito Nacional/Global, tanto do ponto de vista do conteúdo, de edição/ enunciação nacional mas ancoragem e produção local, como do ponto de vista do território, já que é possível conhecer outras identidades e realidades que estão inseridas em um contexto diversificado.

Do ponto de vista da identidade, a forma de representação que o Brasil em Rede produz, remete ao pluralismo e à diversidade do Brasil, apontando para a existência de várias realidades do cidadão brasileiro e dos muitos "Brasil" existentes, assim como haveria muitas Minas narradas na literatura, e nas narrativas do jornalismo audiovisual das emissoras públicas. Se a curta experiência é entendida de forma positiva, pela potencialidade de apresentação de um jornalismo audiovisual mais diverso, e próximo da experiência local, é importante refletir sobre a limitação de seu alcance como alternativa efetiva, considerando que há parcela significativa da população ainda sem acesso a internet em banda larga, com qualidade compatível à fruição de materiais de jornalismo audiovisual. Este mineiro, brasileiro, ainda que fosse representado, teria dificuldades para acessar o conteúdo diverso.

Como telejornal nacional, o Brasil em Rede tem seu raio de alcance limitado aos cidadãos de Minas Gerais alcançados pelo sinal da Rede Minas ou que tem acesso ao ambiente online. Para atuar plenamente como o telejornal nacional que se propõe a ser, o Brasil em Rede precisa atravessar zonas de sombra e silêncio, que ainda são grandes em um país em que 25,1\% da população acima de 10 anos não está conectada à rede (PNAD Contínua - Pesquisa Nacional por Amostra de Domicílios Contínua de 2018).

\section{Revista ALTERJOR}

Grupo de Estudos Alterjor: Jornalismo Popular e Alternativo (ECA-USP)

Ano 11 - Volume 02 - Edição 24 - Julho-Dezembro de 2021 Av. Professor Lúcio Martins Rodrigues, 443, Cidade Universitária, São Paulo, CEP: 05508-020 


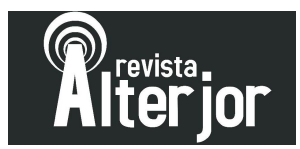

\section{Referências}

CANCLINI, Néstor García. Diferentes, desiguais, desconectados: mapas de interculturalidade. Tradução Luiz Sérgio Henriques. $2^{\mathrm{a}}$ edição. Rio de Janeiro: Editora UFRJ, 2007.

COELHO, Rafael Senra; MONTEIRO, André; ZIMBRÃO, Teresinha. Imanência e transcendência na mineiridade. Revista da Anpoll n n 41, p. 75-86, Florianópolis, 2016.

COUTINHO; EMERIM. - In: COUTINHO, EMERIM (Orgs.). Telejornalismo local: teorias, conceitos e reflexões. Florianópolis: Insular, 2019. p.23-40. (Coleção

Jornalismo e Audiovisual, v. 8).

COUTINHO, Iluska. O telejornalismo narrado nas pesquisas e a busca por cientificidade: A análise da materialidade audiovisual como método possível. In: Anais eletrônicos [...] XXXIX Congresso Brasileiro de Ciências da Comunicação, 2016, São Paulo, SP. São Paulo, USP, 2016. Disponível em:

$<$ http://portalintercom.org.br/anais/nacional2016/resumos/R11-3118-1.pdf>.

HAESBAERT, Rogério. Região, Diversidade Territorial e Globalização. Volume 1, número 1, Niterói. Revista Geografia- Revista do Programa de Pós-Graduação da UFF, 1999.

MARTÍN-BARBERO, Jesús. Ofício de Cartógrafo: travessias latino-americanas da comunicação na cultura. Tradução Fidelina González. São Paulo: Editora Loyola, 2004.

MOREIRA, Sônia Virgínia; DEL BIANCO, Nélia Rodrigues. Brasil: Regiões de sombra e de silêncio no audiovisual e nas telecomunicações. Anais eletrônicos [...] $\mathbf{4 1}^{\mathbf{0}}$ Congresso Brasileiro de Ciências da Comunicação. Joinville, SC, 2018. Disponível em: <http://portalintercom.org.br/anais/nacional2018/resumos/R13-1821-2.pdf > .

OLIVEIRA, Anelito de. A condição mineira: Drummond e a cultura do Barroco. Revista USP, São Paulo, n. 114, p. 159-170, 2017.

ROCHA, Simone Maria. Identidade regional, produção e recepção: a "mineiridade" na televisão. In: Anais eletrônicos [...] Congresso Nacional de Pós-graduação em Comunicação - compós, 12. Recife, PE, 2003. Disponível em:

$<$ http://www.compos.org.br/data/biblioteca_1026.PDF $>$.

THUSSU, Daya Kishan. Media on the Move: Global flow and contra-flow. 2 Park Square, Milton Park, Abingdon, Oxon. Routledge, 2007.

VIZEU, Alfredo; CERQUEIRA, Laerte. O "lugar de referência" do telejornalismo local: o papel dos saberes, dos dispositivos didáticos e da temporalidade. In: COUTINHO, EMERIM (Orgs.). Telejornalismo local: teorias, conceitos e reflexões. Florianópolis: Insular, 2019. p.41-60. (Coleção Jornalismo e Audiovisual, v. 8).

VIZEU, Alfredo. O lado oculto do telejornalismo. Salvador: Calandra, 2005.

\section{Revista ALTERJOR}

Grupo de Estudos Alterjor: Jornalismo Popular e Alternativo (ECA-USP)

Ano 11 - Volume 02 - Edição 24 - Julho-Dezembro de 2021 Av. Professor Lúcio Martins Rodrigues, 443, Cidade Universitária, São Paulo, CEP: 05508-020 